\title{
Uniqueness in Mathematical Limit and Consistency of Socialist Road with Chinese Characteristics
}

\section{-On the Ideological and Political Connotation of Mathematical Limit}

\author{
Zhonghui Xue, Qianfeng Ma, Fenglun Wei \\ Shanghai Publishing and Printing College, Shanghai, China \\ Email: hnlgxzh@163.com
}

How to cite this paper: Xue, Z.H., Ma, Q.F. and Wei, F.L. (2019) Uniqueness in Mathematical Limit and Consistency of Socialist Road with Chinese Characteristics. Open Access Library Journal, 6: e5986. https://doi.org/10.4236/oalib.1105986

Received: December 9, 2019

Accepted: December 23, 2019

Published: December 26, 2019

Copyright $\odot 2019$ by author(s) and Open Access Library Inc.

This work is licensed under the Creative Commons Attribution International License (CC BY 4.0).

http://creativecommons.org/licenses/by/4.0/

\begin{abstract}
Starting from the fact that the independent variable in calculus approaches a certain value infinitely in one direction, the uniqueness of the dependent variable's simultaneous infinite approximation function value and the importance and unshakability of the approach direction, the students are guided to think that "only by adhering to the socialist road can the Chinese dream of the great rejuvenation of the Chinese people be realized". This paper attempts to combine the importance of direction selection in the limit theory with function subsection. It explains Marx Lenin doctrine and Mao Zedong thought, guiding the Chinese people to go out for a long night, building a new China and carrying out the socialist revolution, so that the socialist road can be established in China, and Deng Xiaoping's theory makes China rich and Xi Jinping's new era of socialism with Chinese characteristics. In these three key stages, the importance and uniqueness of adhering to the road of socialism with Chinese characteristics has become stronger.
\end{abstract}

\section{Subject Areas}

Education, Mathematical Analysis, Politics

\section{Keywords}

Limitation, Socialism with Chinese Characteristics, Uniqueness, Consistency

\section{1. 前言}

微积分中的极限知识是微积分学习的重要基础。对极限的理解一方面关系到 
函数连续性、导数、微分和积分等内容的学习, 更为重要的是可以把这种人 类文明的极限思想融入到对学生世界观和价值观的教育中去, 形成对中国特 色社会主义理论体系、制度设计和道路的深刻理解和把握。有关微积分极限 思想的论文多不胜数, 概括起来主要有以下观点: 1). 极限思想蕴含着丰富的 马克思唯物辩证法思想 [1]; 2). 极限思想引申出的工匠精神和探索精神。借 助极限思想, 人们可以更加科学的理解从 “有限认识无限” , 从 “不变” 感 受 “变” , 从 “直线” 理解 “曲线”, 从量变去认识质变, 从近似认识精确 [2]。其实, 站在更高的角度从新审视极限概念和数学符号表达式, 会发现除 了上面谈到思想和哲学价值之外, 还有更高格局和格调的思想价值和现实意 义, 如变量的变化过程, 可以解读为不断努力追求理想的过程, 要求追求理 想的人需要鉴定理想和信念、“永远向理想靠近而不停止”, 坚定而不动摇。 从这个视角, 可以说极限是一个动态函数而不是静态函数, 是过程函数而不 是状态函数。

习总书记在 2018 年纪念改革开放 40 周年大会上指出 “建立中国共产党、 成立中华人民共和国、推进改革开放和中国特色社会主义事业, 是五四运动 以来我国发生的三大历史性事件, 是近代以来实现中华民族伟大复兴的三大 里程碑。”可以简单描述如下:

1) 以毛泽东同志为主要代表的中国共产党人, 创立了毛泽东思想, 完成了 新民主主义革命, 建立了中华人民共和国, 确立了社会主义基本制度。

2) 以邓小平同志为主要代表的中国共产党人, 创立了邓小平理论, 成功开 创了中国特色社会主义。

3）以江泽民同志为主要代表的中国共产党人, 形成了 “三个代表” 重要思 想, 成功把中国特色社会主义推向 21 世纪。

4) 以胡锦涛同志为主要代表的中国共产党人, 形成了科学发展观, 成功在 新的历史起点上坚持和发展了中国特色社会主义。

5) 以习近平为核心的中国共产党人, 形成了新时代中国特色社会主义思想, 推动中国特色社会主义进入了新时代。

本文尝试结合微积分的极限基础知识, 阐释在求解函数极限过程中, 自变 量变化方向的重要性和函数极限值的唯一性与坚持社会主义道路的重要性和 共同理想的唯一性之间的哲学联系, 探究对处在 “拔节孕穗” 期的青年学子 如何树立 “道路自信、制度自信和理论自信”。

\section{2. 数学中极限思想的发展过程简介}

极限思想是一种重要的数学思想。极限思想的萌芽时期可以追溯到 2000 多年 前, 古希腊著名的哲学家芝诺, 提出了这样一个悖论, 那就是 “飞矢不动” , 这是人类第一次闯进极限这个领域。17 世纪, 牛顿和莱布尼茨分别创立了微 积分, 微积分的理论基础是极限论。此时极限概念虽然被提出来了, 但是缺 乏严格的定义。为了解决微积分存在的缺陷, 在十八至十九世纪, 数学家们 寻求解决的办法。其中, 柯西做出了开创性的工作, 比较系统的阐述了极限 理论。但是, 柯西给出的极限定义仍是描述性语言, 缺乏严密性。例如: 要 多小就有多小、无限趋近等描述性词语仍被使用。最后, 维尔斯特拉斯把极 限定义代数化, 实现了彻底严密化和公理化, 即今天我们在大部分的《微积 分》教材中看到的 “ $\mathcal{E}-\delta$ ” 数学语言, 是维斯特拉斯于 1856 年在柏林大学的 
一次讲演中提出的, 它标志着极限理论公理化的完成。极限思想的发展历程, 充分体现了人类探索真理、追求创新的宝贵精神, 充分体现了人类认识世界 和改造世界的强烈愿望[3]。

从上面有关极限理论的发展历史可以看出, 极限理论的发展经历从模糊到 清晰, 从不规范到规范的严格化和理论化一个曲折的发展历程, 但总体趋势 是一步一步的靠近真理的。如从古代中国的 “割圆术” 与西方的 “穷竭法” 相继, 再到牛顿、莱布尼兹对极限的自然语言的描述, 直到波尔查诺、柯西 与维尔斯特拉斯建立起来公理化的极限理论。应该说人类建立极限严格定义 的道路是曲折的, 经历了无数数学家 “一次次的提出概念、一次次的修改乃 至推翻概念” 的探究过程。尽管现代的极限概念已经较为严格, 但这并不意 味着概念发展的历史终结。

\section{3. 数学中极限基本知识简介}

一般来讲, 微积分中求极限包含两类: 数列的极限和函数的极限。根据函数 理论, 数列属于较为特殊的函数, 即离散函数。因此从广义的函数论来看, 可以把以上两种情况统一起来研究, 都称之为函数的极限, 进而把求函数极 限的表达式统一用数学符号表示为:

$$
\lim _{x \rightarrow x_{0}} f(x)=A, \quad x_{0} \in( \pm \infty,-\infty,+\infty, a)
$$

其中 “ lim” 表示求极限符号、“ $x$ ” 表示自变量、“ $f(x)$ ” 表示自变量 “ $x$ ” 的函数、“ $\rightarrow x_{0}$ ” 表示自变量 “ $X$ ” 的变化趋势和方向、“ $A$ ” 表示求解所得 的函数 “ $f(x)$ ” 的极限值。当研究数列极限时, 即 “ $x_{0}$ ” 的取值为取正整数 或 “ $\pm \infty$ ”; 当研究函数极限时, “ $x_{0}$ ” 可以取无穷大和有限值 “ $a \in(-\infty,+\infty)$ ”, 数学语言表达如下, 其中 $B 、 C 、 D 、 E$ 和 $F$ 分别表示求 解所得的函数 “ $f(x)$ ” 的极限值, 当然可以用其他字母或符号来代替。

$$
\begin{gathered}
\lim _{n \rightarrow \infty} x_{n}=B \\
\lim _{x \rightarrow x_{0}} f(x)=C \\
\lim _{x \rightarrow \pm \infty} f(x)=D \\
\lim _{x \rightarrow+\infty} f(x)=E \\
\lim _{x \rightarrow-\infty} f(x)=F
\end{gathered}
$$

从两类典型(数列和函数的极限)极限的表达式可以看出, 求函数极限需要 极限符号、函数、自变量及自变量变化的方向道路, 我们不妨把它称为求极 限的三要素。三个要素一旦确定下来, 函数的极限值也就唯一确定, 这就是 所谓的极限唯一性。三要素的数学符号为: $\lim , f(x), x \rightarrow x_{0}$ 。显然, 极限是 与自变量变化趋势密切相关, 或者说自变量选择的无限趋近方向(道路)紧密 相关, 自变量沿着不同的道路变化, 即使函数的表达式相同, 即同一个函数 $f(x)$ (该出是指函数的解析表达式相同), 函数极限值也不同, 这说明函数的 极限具有和自变量变化方向(道路)的唯一性相关, 当然这也是狭义函数论中 函数定义的要求。 


\section{4. 极限和中国特色社会主义之间的模式关系}

马克思曾明确指出: “一门科学, 只有当它成功地运用数学时, 才能达到真 正完善的地步。” 这是对数学作用的深刻理解, 也是对科学化趋势的深刻预 见。美国数学史家怀特海指出 “只有将数学应用于社会科学的研究之后才能 使得文明社会的发展成为可控制的现实”。中国特色社会主义理论体系是马 克思科学社会主义理论和当代中国实际相结合的理论体系, 既是一种指导中 国人民进行社会主义伟大实践和伟大探索的理论体系也是一门有关中国社会 发展的科学体系。

在探究如何利用科学的极限基础知识和理论在对中国特色社会主义进行阐 释之前, 我们不妨先做一个对应关系的释义, 以方便下面的阐释。

$$
\text { 极限三要素 }=\left(\begin{array}{l}
\lim \\
f(x) \\
x \rightarrow x_{0}
\end{array}\right) \Leftrightarrow\left(\begin{array}{l}
\text { 中国特色社会主义制度 } \\
\text { 中国特色社会主义理论 } \\
\text { 中国特色社会主义道路 }
\end{array}\right)=\text { 中国特色社会主义 }
$$

(1) $\lim$ 对应于制度自信

(2) $f(x)$ 对应于理论自信

(3) $x \rightarrow x_{0}$ 对应于道路自信

数学中的求极限思想对应于我们中国特色社会主义伟大旗帜; 求函数极限 公式中的三要素其实就是 what、why 和 how; 求极限符号 “lim” 表示的是要 做什么, 即 “what”, 它对应于 “中国特色社会主义制度” , 即我们要建设 的是 “社会主义制度” 而不是别的什么制度; 函数符号 “ $f(x)$ ” 表示的是为 什要做, 即 “why”, 它对应于为什要建设 “中国特色社会主义制度” , 即 中国特色社会主义理论, 中国特色社会主义理论全面回答了我们为什么要坚 持中国共产党的领导, 为什么要坚持中国特色社会主义制度, 为什么要坚持 中国特色社会主义道路等重大问题; 而符号 “ $x \rightarrow x_{0}$ ” 表示的怎么做, 即 “how”，它对应于 “中国特色社会主义道路”。中国特色社会主义道路为 中国特色社会主义制度提供路径支撑, 是中国特色社会主义道路实现途径, 中国特色社会主义理论体系为中国特色社会主义道路和中国特色社会主义制 度提供行动指南, 中国特色社会主义制度为中国特色社会主义道路提供制度 保障。三者统一于中国特色社会主义伟大实践, 这是党领导人民在建设社会 主义长期实践中形成的最鲜明特色。

\section{5. 极限唯一性蕴含的 “道路自信”}

如果当 $x \rightarrow x_{0}$ 时 $f(x)$ 的极限存, 那么这个极限是唯一的。上面这句话是数学 教科书中的极限唯一性定理。极限唯一性定理了说明三个关键: 1) 求极限时 $x \rightarrow x_{0}$, 也就是自变量的变化趋势; 2) 极限存在; 3) 极限值的唯一和自变 量的变化趋势对应统一。

对于一个函数 $f(x)$ 来讲, 如果自变量 $x$ 无限趋近的方向不一样, 所得的结 果大不相同。如函数 $f(x)=\frac{\sin x}{x}$, 当自变量 $x$ 的变化趋势为 $x \rightarrow 0$ 时, $\lim _{x \rightarrow 0} f(x)=\lim _{x \rightarrow 0} \frac{\sin x}{x}=1$; 相反 $x \rightarrow \pm \infty$ 时, $\lim _{x \rightarrow \pm \infty} f(x)=\lim _{x \rightarrow \infty} \frac{\sin x}{x}$ 可取值的范围 在开区间 $[-1,1]$, 根据极限唯一性定理, 该函数没有极限。再比如函数 
$f(x)=x^{2}$, 假如不事先确定自变量的变化趋势, 即自变量 $x$ 的沿着哪条道路 趋近一个值, 而是问该函数有没有极限, 回答有或没有都对。比如上面的例 子 $\lim _{x \rightarrow 0} f(x)=\lim _{x \rightarrow 0} \frac{\sin x}{x}=1$ 和 $\lim _{x \rightarrow \infty} f(x)=\lim _{x \rightarrow \infty} \frac{\sin x}{x}$ 没有极限, 道理同上, 不在赘 述。从极限的概念和唯一性定理可以看出, 努力方向和道路选择有何等重要, 就好比你拥有了利器, 也知道利器的使用方法, 但是利器指向不对, 也只能 事倍功半, 甚至于把事情办得一塌糊涂。这个古人 “工欲善其事, 必先利其 器” , 殊途同归, 其实我们还可以加上两句 “器欲尽其能, 必先得其领” 。 俗语说得好 “方向不对, 努力白费”、“既要低头拉车, 还要抬头看路” 说 的都是道路的重要性。

清朝的文学家袁枚写的《续诗品. 尚识》有关方向的重要性有过这样的诗句, “学如弓驽, 才如箭镞。识以领之, 方能中鹄”。愿意是说学问就像弓一样, 是用来施加作用和发力的, 比如函数极限表达式中的 “ $P$ ”; 才华像箭头, 比 如函数极限中的符号 “ $x \rightarrow$ ”, 是用来刺穿的工具。有了这个弓, 就比如有 了 “ $f$ ”, 再有了箭, 比如有了 “ $x \rightarrow$ ”, 是不是就能射中靶子啊? 恐怕不行 吧! 还必须有方向, 就像 “ $x \rightarrow$ ” 的方向要设定。方向是什么呢? 方向就是 箭要飞行的轨迹、道路, 数学上来讲就是 “ $x \rightarrow x_{0}$ ”, 有了正确的思想和坚 持走正确的道路, 即引领, 再引弓发力, 然后再有箭去穿刺, 这样才能够一 举中的, 射中靶子。

熟悉近代史的中国人都知道, 随着 1840 年鸦片战争的失败, 仁人志士开始 了救国救亡的道路探索。从 “公车上书” 的 “戊戌变法” 到 “实业救国” 的 “洋务运动” , 再到孙中山先生领导的 “辛亥革命”, 一个接一个的道路探 索都失败了, 都没有能够救人民于水火, 救民族于赢弱, 救国家于存亡, 都 没有能够让中国站起来, 富起来和强起来。我们共产党人做到了, 为什么? 最根本的就是我们不但做到了 “工欲善其事, 必先利其器, 器欲尽其力, 必 先准其矢” , 而且坚持只有社会主义道路才能救中国, 走的是社会主义道路。 用极限术语表示如下: 党的领导是方法即 “极限方法” , 求极限走的道路是 社会主义道路, 所得结果就是国家站起来、富起来和强起来。下面我们试着 用极限的方法把三个重要阶段用极限的数学符号表示如下:

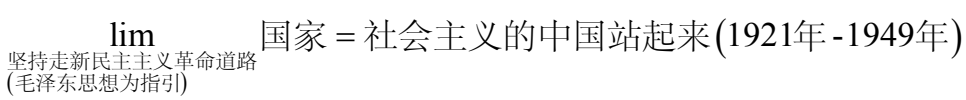

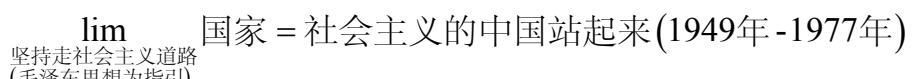

$$
\begin{aligned}
& \text { (年择东思想为指引) }
\end{aligned}
$$

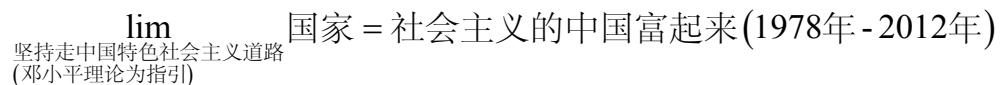

坚持走新时代中国特色社

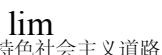

国家 $=$ 社会主义的中国强起来(2012年 - 2050年) (4) (习近平新时代中国特色社会主义思想为指引)

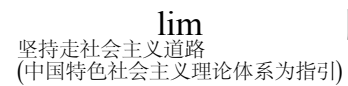

$$
\text { 国家 }=\text { 实现共产主义理想 }(2050 \text { 年 - ） }
$$

站起来。1949 年, 毛泽东一声 “中国人民站起来了” , 多少中华儿女热泪 盈眶、热血沸腾, 中华民族终于挺直腰杆站了起来。只有社会主义才能救中 国, 也只有社会主义才能发展中国, 社会主义是当代中国一切发展进步的根 本政治前提和制度基础。社会主义要在中国取得成功, 必须改革开放, 走中 
国特色发展道路。

富起来。邓小平一句 “贫穷不是社会主义”, 醍醐灌顶, 振狵发聩。经过 改革开放以来的不解奋斗, 中国经济实力、科技实力、国防实力、综合国力 进入世界前列, 国际地位实现前所未有提升。尽管如今全球经济发展深层次 矛盾凸显、国际环境不稳定不确定因素增多, 中国经济却一直保持稳步增长, 国内生产总值稳居世界第二, 对世界经济增长贡献率超过 30\%。中华民族终 于逐渐富了起来。

强起来。中共十八大以来, 中国发展站到了新的历史起点上, 中国特色社 会主义进入了新的发展阶段。中华民族强筋壮骨, 日益强起来。习近平总书 记说, 现在, 我们比历史上任何时期都更接近实现中华民族伟大复兴的目标, 比历史上任何时期都更有信心、有能力实现这个目标。

从站起来、富起来到强起来的历程, 让中国人民坚信, 只要跟着中国共产 党走社会主义道路, 中国就有更光明的未来。可以预期, 近 14 亿中国人民将 在中国共产党带领下, 高举中国特色社会主义旗帜不解奋斗, 决胜全面建成 小康社会, 开启全面建设社会主义现代化国家新征程, 逐步实现全体人民走 向共同富裕, 彻底完成中华民族从站起来、富起来到强起来的伟大历史性飞 跃。

何为 “道路自信” ? 习近平在中国共产党的十九大报告中指出：“中国特 色社会主义是实现社会主义现代化、创造人民美好生活的必由之路。” 实践 证明, 中国特色社会主义道路相对于苏联模式是可持续发展的, 相对于拉美 模式是稳定发展的, 相对于东亚模式是自主发展的, 相对于欧美模式是快速 发展的。坚定不移的走社会主义道路是建立在人类社会运动 “规律” , 尤其 是资本主义社会基本矛盾运动 “规律” 基础上, 反映了历史发展的必然趋势 和人们最广泛的美好愿望。

辛万鹏、路娜娜在《论道路自信来源的四个维度》一文中提出道路自信的 根本在于道路本身的科学性和真理性的论述, 具有很好的借鉴意义 [4]。像极 限理论一样, 中国特色社会主义道路是中国特色社会主义理论体系的重要部 分, 是马克思科学社会主义理论和我国具体时间相结合的产物, 是一门科学; 其次, 都是对真理的极限描述, 都把实践作为检验真理的唯一标准。我们共 产党人的最高理想是实现共产主义, 实现全人类的解放, 就是我们的最高极 限, 也是我们的共同信仰。

习近平我们党始终坚持共产主义远大理想, 共产党员特别是党员领导干部 要做共产主义远大理想和中国特色社会主义共同理想的坚定信仰者和忠实践 行者。对马克思主义的信仰, 对社会主义和共产主义的信念, 是共产党人的 政治灵魂, 是共产党人经受住任何考验的精神支柱。党章明确规定, 党的最 高理想和最终目标是实现共产主义。党章同时明确规定, 中国共产党人追求 的共产主义最高理想, 只有在社会主义社会充分发展和高度发达的基础上才 能实现。想一下子、两下子就进入共产主义, 那是不切实际的。邓小平同志 说, 巩固和发展社会主义制度, 还需要一个很长的历史阶段, 需要我们几代 人、十几代人、甚至几十代人坚持不解地努力奋斗。几十代人, 那是多么长 啊! 从孔老夫子到现在也不过七十几代人。这样看问题, 充分说明了我们中 国共产党人政治上的清醒。必须认识到, 我们现在的努力以及将来多少代人 的持续努力, 都是朝着最终实现共产主义这个大目标前进的。同时, 必须认 
识到, 实现共产主义是一个非常漫长的历史过程, 我们必须立足党在现阶段 的奋斗目标, 脚踏实地推进我们的事业。如果丢失了我们共产党人的远大目 标, 就会迷失方向, 变成功利主义、实用主义。中国特色社会主义是党的最 高纲领和基本纲领的统一。中国特色社会主义的基本纲领, 概言之, 就是建 立富强民主文明和谐的社会主义现代化国家。这既是从我国正处于并将长期 处于社会主义初级阶段的基本国情出发的, 也没有脱离党的最高理想。我们 既要坚定走中国特色社会主义道路的信念, 也要胸怀共产主义的崇高理想, 矢志不移贯彻执行党在社会主义初级阶段的基本路线和基本纲领, 做好当前 每一项工作。实现远大理想的是一个需要几代, 甚至十几代、几十代人在实 现远大理想的路上, 我们分段进行, 分段求极限。以党的思想的指引, 以信 仰为力量, 坚定不移的选择社会主义道路做实践和不断积累, 理想终将实现。 不难看出, 历史上任何一项重大理论的完成都要经历一段时间一样, 作为科 学化的中国社会主义一样经历的实践的检验。习近平 “事实一再告诉我们, 马克思、恩格斯关于资本主义社会基本矛盾的分析没有过时, 关于资本主义 必然消亡、社会主义必然胜利的历史唯物主义观点也没有过时。这是社会历 史发展不可逆转的总趋势, 但道路是曲折的” 《求是》杂志发表习近平总书 记重要文章《关于坚持和发展中国特色社会主义的几个问题》。比如牛顿和 莱布尼茨整理完成的微积分理论也都是很不完善的。特别在无穷和无穷小量 这个问题上, 其说不一, 十分含糊。牛顿的无穷小量, 有时候是零, 有时候 不是零而是有限的小量; 莱布尼茨的也不能自圆其说。这些基础方面的缺陷, 最终导致了第二次数学危机的产生。微积分诞生之后, 数学迎来了一次空前 繁荣的时期。对 18 世纪的数学产生了重要而深远的影响。但是牛顿和莱布尼 茨的微积分都缺乏清晰的、严谨的逻辑基础, 这在初创时期是不可避免的。 通过纵横对比, 更加容易认识到中国特色社会主义道路是唯一正确的道路, 中是中国共产党人的伟大创造, 体现了历史的选择, 反映着人民的意愿, 是 实现社会主义现代化的必由之路, 是实现强国富民、民族复兴的必由之路。 一个国家、一个民族、一个政党如果没有明确的发展方向、没有明确的指导 思想就会陷入迷途，难有光明前景。

从函数的连续性和函数极限的关系可知, 连续函数必有极限。因为中国特 色社会主义理论的 “一脉相承” , 我们伟大的中国特色社会主义事业才会薪 火相传, 并在一茬接着一茬的努力奋斗中不断地走向新高。

\section{6. 结论}

函数极限理论建立的过程是曲折, 从最初的语言文字描述到完善的数学语言, 最终建立了一套完整的理论, 为微积分大厦铸就了坚实的地基。中国特色社 会主义理论体系也是在一代又一代共产党人的前仆后继的求索取得的伟大理 论。而求极限的关键是自变量变化方向的确定、道路的坚持, 即自变量变化 时所坚持的方向和道路。建设中国特色社会主义制度关键是在中国共产党的 领导下坚持走中国特色社会主义道路不动摇。在坚持马克思主义理论自信的 基础上不断的中国化和完善, 从伟大的毛泽东思想到邓小平理论, 从三个代 表到科学发展观, 再到习近平新时代中国特色社会主义理论, 正是在坚持道 路自信、理论自信和制度自信的基础上解决了一个又一个极限, 从一个胜利 走向了另一个胜利。 


\section{项目说明}

薛中会, 男, 博士, 副教授, 资助项目: 上海出版印刷高等专科学校 2019 年 高教研究所立项课题: 高职高专 “人工智能+数学” 人才教学改革研究, NO.SPPCGJS-16; 上海出版印刷高等专科学校 2019 年度校内思政课题: 人工 智能+大思政视域下协同育人研究。2018 年度教育部高校示范马克思主义学 院和优秀教学科研团队建设项目 (18JDSZK012)；2019 年上海出版印刷高等专 科学校三期课程思政改革试点滚动支持项目。

\section{Conflicts of Interest}

The authors declare no conflicts of interest regarding the publication of this paper.

\section{References}

[1] 叶林. 哲学与数学史视域中的极限思想探析 [D]: 硕士学位论文. 济南: 山东大 学, 2008 .

[2] 王保伦. 极限概念的逻辑特征 [J]. 辽宁工程技术大学学报, 1983(2): 75-82.

[3] 曾晓明. 极限概念是唯物辩证法思想的光辉体现一一兼评《新微积分浅说》[J]. 东 北大学学报(自然科学版), 1976(2): 98-105.

[4] 辛万鹏, 路娜娜. 论道路自信来源的四个维度 [J]. 学理论, 2017(5): 17-18. 